\title{
Self, Family, and Society: Three Kinds of Employment Value for College Students
}

\author{
Hui-Ju YU* \\ ${ }^{1}$ Maxism School of Zhejiang University, Hangzhou, China, 310028 \\ ${ }^{2}$ Humanity School of Hangzhou Normal University, Hangzhou, China, 311121 \\ Email: yhj@hznu.edu.cn \\ *Corresponding author
}

Keywords: Value of employment, Self-value, Family value, Social value.

\begin{abstract}
The psychological reason of employment difficulties for college students today is value imbalance and dilemma in employment. College students hope to realize their self-value, familyvalue, and socialvalue in employment, which reflects their pursuit for the ideal life. Back to ancient agricultural China with the conventional culture, one's family value of employment was emphasized, while self-value and social value were ignored or weakened. This value-imbalance gradually became the obstacle for the employment of college students who lived up in a multicultural environment and had been experiencing great changes in China's social transformation. To solve this psychological problem and promote employment of college students, we should help them to balance the three kinds of values for employment by making self-value clear, taking responsibility for family-value rationally, and making devotion for social-value.
\end{abstract}

\section{Introduction}

The difficulties of employment for college students have been concerned by the whole society in China. With the impulse of mass media emphasizing "the most difficult employment year"," more difficult employment season", "the most difficult season in the history", deep anxiety has spread from college to thousands of families. The reasons for the difficulties of employment for college students should be investigated, and strategies should be proposed to handle these difficulties.

It is generally believed that the difficulties lied in the stringent demands put forward by units, gender discrimination, "connections" and "back doors" in the marketization of graduate employment, the system and policies restrictions(Di Feng,2002; GaiShizhou,2014). However, most of these research only considered the external causes, and little attention had been paid to the internal causes of college students.

According to dialectical materialism, external causes are the conditions of the development of material, while internal causes are the basis of the changes of material, external causes only function when internal causes function. As the main bodies of employment in the labor market, college students' internal causes, such as conceptions, expectations, values, can't be ignored.

China has been experiencing the most important and greatest transformation and reform. Accordingly, the ideas and values of Chinese people are changing. In traditional society, employment mean solving livelihood problems; while in modern society its meaning becomes more complex and multivariate. College students are facing with so many puzzles and value dilemmas in the transformation, which should be taken into consideration for the reasons and solutions of employment difficulties.

\section{Three Value Dilemmas in the Employment of College Students}

College students in different historical period have different value choices. When the entrance examination for college first restored, college students fully obey the needs of the nation. In 1985, the national policy for college students' employment changed, the government couldn't assign jobs 
for college students. As the result college students had to look for jobs facing with the needs of employment units. Students began to seek for the combination of national needs and personal needs from the employment (Cao, 2014). Not until the ends of 1990s, the college students had completed the transformation from assignment to self-employment, while their values of employments had gradually been reconstructed. They had shown strong sense of self-orientation than socialorientation in the course of employments (Wu, 2013).

\section{Self-Value: Blind and Materialized}

Self-value is the value of "ego" rather than the value of personal willing. It should be well developed on the base of the self-consciousness, cautiously chosen in the course of value clarification. In modern society college students are much more caring about "themselves". According to the interview by Wang(2006) in Zhejiang University, all 18 college students chose "highly paid, at least feed themselves"; 16 of them chose "working in economically-developed area"; 14 of them chose "personal ability can be thought highly and developed", which indicated the standards in employment-decision for college students were becoming more and more practical and materialized (Wang, 2006). In another investigation by $\mathrm{He}(2002), 39.7 \%$ college students chose to work in high-paid units, parts of college students even agreed with opinion "Money is more valuable than the ideal, Wealth is more important than talent". Economic-developed cities and areas were their first choice when looking for jobs. The value of college students is going to being commercialized and pragmatic. In other words, the college students' values of employment are inclined to practical life and materialized rather than themselves.

\section{Family Value: Influence Deeply}

In Chinese society, family has been playing an important role which showed special meanings and deep emotional identity in Chinese people. It influenced the growth of people in families. Deeply rooted in the traditional culture of China, the elders used to educate young people of the families, while young people had to obey to the elders. This situation hasn't been changed in modern society(Li,2011). According to the statistics, 55\% of college students were deeply influenced by their parents, $41 \%$ of them got information about employment from parents and relatives, only $16 \%$ of them got information from talent market by themselves (Liu, 2010).So parents' values have been greatly effecting their children's values, including employment values.

Parents often value high social status, stable lifestyle and good social reputation in their children's employment, paying few attention to their kids' interests, specialty and value. Civic servants, teachers, staff of state-owned enterprises, etc. are the priorities in parents' view, who hope their kids can have stable employment and bright career.

Affected by Chinese family culture, college students would take family interests and parents' feelings into account when hunting for jobs. Even small part of students attributed their goals of going to university were for their families and parents, and chose some job according to family preferences.

\section{Social Value: Be Ignored}

With the rapid development and huge transformation in China nowadays, people's thoughts and values have already changed a lot. The global informatization caused de-centerlization and individualism. People pay much attention to themselves and the surroundings, while care less for the public interests and social development. Some people even think the public interests and social development have nothing with them. The traditional value of society-centered from 1949 changed gradually, self-centered value took advantage over it, which caused the society and its value often be ignored by college students.

According to the survey by Shi (2010), 29.36\% of college students clearly declared they weren't willing to be teachers in the basic level, nor western areas of China or other underdeveloped areas. An investigation showed that when faced with the question "what will you do when your choice conflict with the nations' needs?”, 50.9\% college students chose “self-realization”(He,2002). Social 
responsibilities and values were ignored inappropriately.

\section{Three Values of Employment: Self, Family and Society}

Unlike employment in European or American culture, Chinese employment has special characteristics and meanings in its special cultures. Chinese employment doesn't only mean finding a job or having a career, it bears more cultural preference and ethnic psychology, which existed from ancient China to modern China.

\section{The Traditional Meanings of Chinese Employment from Chinese Characters}

In Chinese character, people use "JiuYe" to point to employment. According to the explanations in the dictionary of Chinese Modern Character, "Jiu" is a verb and also an adj., which means to start and to complete. "Ye" not only means job, but also means academic, property, enterprise and industry, et. So "Jiu Ye" means to start and to complete academic, property, career, enterprise and industry, et. which inspired us with two following ideas at least:

First, Chinese employment not only means to start a job or career, but also points to the completed state through various efforts of long periods, such as academic, property, enterprise and industry. Second, Chinese employment emphasize the co-force of academic, property, career, enterprise and industry, et. Which relate and influence each other. Each one of them can be the start, and can promote others. Harmonious co-existence and promotion between each other are their meanings.

So the common conception that “employment is just finding a job” isn't right, employment has more various and cultural means. The thought of some college students that "the first job is the last job” is also absurd.

\section{The Psychological Preference in Chinese Traditional Culture}

In ancient China, people began to pay attention to the three meaning of employment. In Chinese characters, people often used "surviving" to replace "employment", which pointed to the personal value from the perspective of living up. "Serving families and feeding children" were also used frequently, which meant the family value of employment. Chinese proverb "Troubled, improve yourself; valued, improve the world" declared the responsibility for the society and the world, which can be called social value. But that not mean people valued equally to the three values of employment in Chinese traditional culture.

In fact, the agricultural culture in ancient China cultivated special family-orientated culture (Lv, 2004). In the long period of Chinese feudal society, most people fed themselves by farming and bound themselves with lands closely, which contributed to the family-centered culture. The surviving, stability and development of the family became the center of the family, while self-value and social value of the employment were marginalized(Lv, 2004). The individual in the family must work, because he must keep other families living; whether the individual came be an official or a businessman, the first goal was to glorify his family, while serving the people and promoting the development of business were ignored or unimportant. This special structure of employment value-family value was emphasized while self-value and social value were ignored-had been deeply influencing the psychology of Chinese people.

Because of the emphasizing family value in employment, Chinese people have strong sense of responsibility for the family. They pursue the "stability" of employment in order to feed their families. In traditional society, Chinese farmers were bound with lands from birth to death, they believed that personal stability in employment could lead to the family's stability and prosperity. The son would inherit from his father to avoid the threat from employment instability. There was an old proverb saying:” Children couldn't travel or work far away when their parents were alive.” The advantage of the employment stability is to avoid risk, protect family and make sure of personal surviving. But one coin has two sides. Stability also caused conservative ideas, weak consciousness of enterprising and missing consciousness of development. 
Because of the emphasizing on the family value in employment, Chinese people have weak sense of self consciousness and values. In family-centered structure, there are only two parts in families, one is parents, the other is families, who were attached to the whole family. The relationship between families was obligation-right, families should act appropriately according to the elderyounger order, which caused ignorance of personal freedom, right and value (Lv, 2004).

Because of the emphasizing family value in employment, Chinese people were so materialorientated and ignorant to social value of employment. In traditional society of China, the subjectivity of obligation and right was family other than individual, so capable and responsible parents had to shoulder the pressure from the other families, thus they had no time to give consideration to the public welfare and responsibility for the country and society (Yang, 1994). Chinese proverb that "Troubled, improve yourself; valued, improve the world" pointed out that individual wouldn't take account to the public welfare and social value until self-realization. The idea of "family and country" vague the difference between family and society, and social value was replaced by family value. All of these contributed to social value degraded.

\section{The Three Kinds of Values in Employment: Self, Family and Society}

From above, we can view values of employment from three perspectives: self, family and society. Self-value of employment means surviving physically, be happy psychologically and self-realizing spiritually. Family value of employment means supporting other families financially, taking care of other families and feeling be needed emotionally. Social value of employment means supplying labours for social production, promoting some industry, creating better social surroundings. Selfvalue, family value and social value are people's needs from different perspectives. They constitute of values of rational citizens, none of which can be deleted, omitted or replaced. People can be happier, more satisfied and more creative if these three kinds of values in employment can co-exist harmoniously. If self-value is ignored or sacrificed, people may become working-crazy, but won't feel happy psychologically and are lack of inner-stimulus from long term. If family-value is deleted, people may feel cruel and guilty for parents and other families, which may decrease satisfaction and devotion in work and hamper one's development. If social value is ignored and degraded, the society we live in will make no progress, the public interests will be destroyed and the later generation will have no way to survive on the earth. So the ideal employment can satisfy people with three kinds of value: self, family and society, which can coexist harmoniously and promote others mutually.

\section{Solutions: Rebuild the Three Kinds of Values in Employment}

Under the background of family-centered structure, college students were facing with so many psychological problems and blocks in the course of looking for jobs. To solve these problems, there's urgent need for college students to rebuild harmonious value structure to get rid of the traditional hinders. The three kinds of values in employment must be emphasized in different ways.

\section{Self-Value: Confirm Actively}

The confirmation of self-value is the foundation for the existence of humanity. Without self-value, family value and social value of employment must be abnormal. In the long history of ancient China, people ignored and suppressed self-value. So it's urgent need for people to confirm his value beforehand. People have to answer three questions.

First is "who I am", which can be called self-consciousness. Only people realize who he is, can he take action with self-discipline, supervise himself and improve himself and come to better self at last.

Second is "what to do", which can be called the goal of career. The characteristics of Chinese parents decide that college students are dependent and passive. They have no clear needs and goals either in the short term or in the long term. In fact, goals can bring people motivation and people have different goals in different periods of life. For college students, clear goals in different periods 
can help them act positively.

Third is "how to be", which can be called the situation of existence. Happiness come from the harmonious coexistence between self and the outer world, and is arrived after self-adjustment and self-clarification when dealing with the outside. It can give people imputes for action and promotions for better development. If college students can make sure of himself and believe in himself, they can accept and hold himself psychologically and be willing to take action.

\section{Family Value: Confirm Rationally}

Family is the smallest unit of the society. Family value is the bridge of the self-value and social value, without which, social value can't come true and persons can't be complete ones. Family values in employment involve sense of responsibility, independence and creativeness.

Everyone has his family and should be responsible for his families. While too much strong sense of responsibility makes people lose themselves, the absence of responsibility makes people selfcentered. The "NEET" phenomenon is the expression of absence of responsibility for family.

Independence means being the master of himself without dependence upon other people or other families. In modern society, family have changed from feudal patriarchy to democracy, the relationship among families isn't the order-obey style before, but respect-equality style, in which personal feeling and thought are emphasized, so dependence of consciousness and action become urgent.

Creativeness points to expansion of living space and idea renewing. The traditional values of employment, such as stability and dependence on the family, are invalid in the informatized society nowadays. Either in the real space or in the virtual world, personal living scales are expanded ever before, people have to step outside from his family and embrace the challenges from the modern world.

\section{Social Value: Confirm Positively}

People live in the society. Their survival and development can't be separated from society. Without social value, people are limited in the small circle constituted of self and family and can't go far away. Social value is the upper realization of self-value and family value. College students should confirm social value positively through establishing the consciousness of unifying, citizenship and devotion.

College students must build up the sense of unifying in spite of opposition. Students must inspect and adjust themselves to suit for the social situations, devote themselves to the industry and make contributions for the social development.

Citizenship means being a master and civic of the society (Xiao, 2008). College students are part of the citizens of the society and benefit from the development and progress of the society. They should show and take their social responsibility from employment.

Devotion means being responsible for the social obligations positively. The great goal of realizing the "Chinese Dream" urge every college student to make their own contributions to the construction of Chinese modernization and informatization in spite of position and wealth.

\section{Summary}

Value imbalances existed in employment of college students in China, which led to the difficulties of employment of college students psychologically. There are three kinds of values in employment: self-value, family value and social value. Through confirming self-value, family value and social value, college students can be true masters of their employments and careers, achieve their selfgoals, prosperous their families, promote social developments and ultimately realize personal freedom and overall growth. 


\section{Acknowledgement}

This research was financially supported by the 2017 Educational Science Program of Zhejiang Province(2017SCG013) and the 2016 National Science Foundation Youth Project(71603067) in China.

\section{References}

[1] Di, F.(2002). Will there be much difficulty in finding employment for 1999 college students, Chinese Education and Society, 35( 1): 28-36.

[2] Gai, S., Liu, Y., Li, W.(2014). Research on the characteristics of promoting methods of the changes for college students' value orientation in employment, China Adult Education,19:62-64

[3] Gao, C., Tian, Z.(2014). The exploration of college students' employment value orientation, Education and Employment,3:92-93

[4]He, D., Li, D.(2002). The investigation and strategy of employment of contemporary college students. Journal of North China Electric Power University (social sciences edition).1:91-93

[5]Li, Z.(2011). The influence of family education culture to employment values of contemporary college students. Journal of Honghe University. 12: 104-106

[6] Liu, C.(2010). Research of psychological problems and influence factors in employment of contemporary college students. Jilin University.

[7] Lv, Y. (2004): The explanation of family-centered and the communication of family-centered and individual-centered, Journal of Zhongzhou, 09:175-178

[8] Ruan, M. (2009). Research of development of employment ability for local college students, Journal of Ningbo University. 31(1):59-62

[9] Shi, Z.(2010) Investigation and research of college students' value orientation of employment. Journal of Chongqing JiaoTong University(philosophy and social sciences edition), 10:96-99

[10] Wang, Y.(2006). Research on the relationship of employment value, employment ability and employment outcomes of college student. Zhejiang University.

[11] Wu, H.(2013). Investigation and research of college students' employment value orientation. Education research and experiment.05:22-28

[12] Xiao, Y.(2008). Education and research of citizenship of college students, Education of Exploration. 12:19-20

[13] Yang, D.(1994). The responsibility and ability of Chinese people, Chinese traditional law culture, Press of Beijing University.

[14] Zeng, H.(2008). The exploration of the current psychological situation in employment and methods of promotion of college students in the western areas of China. Southwest JiaoTong University. 